\title{
EL PATRIMONIO ARQUEOLÓGICO Y SU IMPORTANCIA EN EL DESARROLLO DEL PERÚ
}

Ruth Shady Solís

\section{RESUMEN}

Ponencia presentada en el Seminario Internacional "Contribución del Control en la Gestión Ambiental y Patrimonio Cultural". Se realizó en la Contraloría General de la República, Lima, del 3 al 5 de junio de 2002. En este documento se aborda la problemática de los bienes arqueológicos en nuestro país, la importancia histórica que ellos representan para cimentar una identidad cultural como nación y también la desaprovechada oportunidad de convertirlos en potenciales ejes de desarrollo; igualmente se señala la falta de una visión política coherente que impida el saqueo y la destrucción de un legado histórico que no puede renovarse.

\section{ABSTRACT}

Paper presented in the International Seminar "Contribución del Control en la Gestión Ambiental y Patrimonio Cultural". It took place in the General Comptrollership of the Republic, from June 3 to June 5, 2002. In this document, the problematic of the archeological goods in our country is treated, the historical importance they represent, to establish a cultural identity as a nation and also the wasted opportunity to become potential development axes; equally it's pointed the lack of a coherent politic vision that prevents pillage and destruction of a historic legacy that can't be renovated. 


\title{
EL PATRIMONIO ARQUEOLÓGICO
}

\begin{abstract}
"Los monumentos arqueológicos, históricos y artísticos constituyen también recursos económicos al igual que las riquezas naturales del país. Consecuentemente, las medidas conducentes a su preservación y adecuada utilización no ya solo guardan relación con los planes de desarrollo, sino que forman o deben formar parte de los mismos" (Carta de Venecia, 1967).
\end{abstract}

$\mathrm{L}$ os peruanos poseemos uno de los patrimonios arqueológicos más ricos y mejor conservados del mundo. Está conformado por los bienes inmuebles (asentamientos, construcciones monumentales, campos de cultivo, canales de riego, caminos, cementerios, etc.), por los bienes muebles (ceramios, textiles, objetos de piedra, madera, hueso, concha, joyas, etc.) y por todos aquellos testimonios de actividades humanas pertenecientes a los períodos comprendidos entre el poblamiento humano del territorio peruano hasta la llegada de los españoles.

\section{PROPIEDAD DEL PATRIMONIO CULTURAL}

Los bienes arqueológicos pertenecen a los integrantes de una nación, pues han sido obras de sus antepasados y testimonian situaciones históricas. Los hereda toda la sociedad sin distinción de edad, sexo, raza, clase o posición social, y le sirven para conocer su historia, aprender lo bueno y no volver a cometer errores del pasado; para cohesionarse e identificarse como nación al compartir la misma historia y tradición cultural; y para promover el desarrollo turístico y generar fuentes de ingreso económico. Por la condición que ellos tienen como bienes patrimoniales de una nación, el estado, como su representante jurídico, y la sociedad civil comparten la responsabilidad de cuidar este legado, revalorarlo, conservarlo y transmitirlo sin ninguna merma a las si- guientes generaciones, a las cuales les asisten los mismos derechos.

\section{IMPORTANCIA DEL PATRIMONIO ARQUEOLÓGICO}

Como hemos señalado, el patrimonio arqueológico tiene tres clases de valores:

1. Histórico, porque a través de los testimonios arqueológicos se puede reconstruir los modos de vida y culturas de las sociedades que los crearon,

2. Cultural, porque permite que los pobladores actuales se identifiquen como pertenecientes a un mismo colectivo, cohesionado por una tradición cultural compartida,

3. Económico, mediante el desarrollo de la actividad turística y la generación de ingresos.

\section{IMPORTANCIA HISTÓRICA DE LAS EVIDENCIAS ARQUEOLÓGICAS}

Constituyen los bienes arqueológicos el único medio de recuperar información sobre más de doce mil años de historia de las sociedades nativas, las cuales, para orgullo nuestro, a pesar de ocupar una de las tierras más accidentadas y contrastadas en cuanto a recursos naturales del planeta, lograron adaptarse exitosamente, crear culturas singulares y llegaron a tener niveles de desa- 
rrollo comparables a los más destacados del mundo. A través de la arqueología hemos podido saber de sus avances en el conocimiento de matemáticas, geometría, astronomía, etc., plasmados en construcciones como la ciudad de Caral, en los albores de la civilización, o en los eficientes sistemas agrícola y vial, que fueron admirados por los europeos en el ocaso del imperio Inca. El Perú no ha podido recuperar todavía la extensión de tierra agrícola que habilitaron las sociedades prehispánicas sobre la base del trabajo colectivo organizado y bajo la conducción de especialistas en manejo de suelos y administración de aguas. Mediante la construcción de terrazas o andenes convirtieron los espacios andinos áridos y accidentados en fértiles campos de cultivo; con el trabajo en camellones hicieron producir las tierras periódicamente inundadas; a través de la excavación de cochas pudieron enfrentarse a las heladas e inclemencias climáticas en los altiplanos y a través de los mahamaes cultivaron en chacras hundidas excavadas, que les permitían aprovechar de la napa freática en territorios desérticos. Gran parte del territorio peruano ha sido modelado por el trabajo milenario de las sociedades prehispánicas que buscaron desarrollar estrategias adaptativas relacionadas con las características propias de cada lugar. No se emplearon procedimientos tecnológicos de otras realidades como suele hacerse en la actualidad. Se usaron tecnologías aplicadas a las condiciones de cada medio geográfico.

Los resultados de esta exitosa productividad hicieron posible, entre otras cosas, la disponibilidad económica invertida en especialistas cuyas obras arquitectónicas monumentales y artísticas pueden admirarse en diversos espacios del territorio nacional.

La arqueología nos enseña, por ejemplo, que el Perú se adelantó en 1500 años en cuanto al conocimiento y a la convivencia organi- zada en los ámbitos económico, social y político, a cualquier otra sociedad del continente americano. Esta tarea de recuperación histórica tiene un doble mérito en sociedades como la nuestra, donde todavía no se han descifrado los registros de información dejados en quipos, tocapus, pallares, etc., que puedan coadyuvar a dar cuenta de los acontecimientos históricos significativos del proceso cultural. A diferencia de los países de Mesoamérica, donde se ha solventado por varias décadas el trabajo de equipos interdisciplinarios para el desciframiento de la escritura Maya y ya se ha avanzado en su lectura, en el Perú sólo se han hecho esfuerzos aislados y estamos lejos de su desciframiento.

\section{IMPORTANCIA CULTURAL DE LOS BIENES ARQUEOLÓGICOS}

Las poblaciones que comparten un territorio e interaccionan en diversas actividades requieren de vínculos de cohesión que garanticen una convivencia sin mayores conflictos. Las manifestaciones culturales compartidas (ceremonias, rituales, mitos, lenguaje, etc.), los modos de vida o formas de relacionarse con el medio circundante geográfico y humano, y la historia de los acontecimientos significativos, transmitida de una generación a otra, constituyen esos lazos de articulación social. Ellos les permiten a los integrantes de una sociedad compartir el sentimiento de pertenencia a una misma nacionalidad; verse a sí mismos como idénticos o como diferentes frente a sociedades con nacionalidades distintas.

En las etapas iniciales del desarrollo humano, por casi cinco millones de años, las relaciones entre los hombres estuvieron dirigidas a proveerse de los recursos necesarios para su supervivencia y se diferenciaron en relación con el sexo, la edad y algunas capacidades personales. Sólo hace cinco mil 
años con el surgimiento de las civilizaciones en únicamente cinco lugares del planeta, Mesopotamia, Egipto, India, China y Caral, Supe, Perú, con la construcción de ciudades y la formación de gobiernos estatales, las sociedades se diferenciaron internamente en estratos jerarquizados y delimitaron sus fronteras territoriales, políticas y culturales. Diferencias que los romanos expresaron calificando a unas como naciones civilizadas y a las otras como pueblos bárbaros; o que los peruanos del área norcentral del Perú llamaron con los términos Huaris, a los civilizados, en oposición a los Llacuaces, salvajes. En nuestros tiempos se denominan países desarrollados versus subdesarrollados o más recientemente desarrollados o en vías de desarrollo; o del primer mundo, tercer mundo, cuarto, etc. Calificativos etnocéntricos que marcan distinciones entre nacionalidades a partir de criterios socioculturales y/o económicos.

Desde el punto de vista antropológico, un sistema cultural es óptimo si permite la adaptación de sus integrantes al medio geográfico y social y garantiza la supervivencia cultural del grupo. En principio no hay sistemas sociales mejores en calidad que otros. Es en la relación entre sistemas y mediante el conflicto militar o la competencia económica que unos se han impuesto sobre los otros y entonces sus miembros pueden exhibir conductas de prestigio o de humillación. $\mathrm{Y}$ en este contexto, en la medida en que cada ser humano necesita de su nacionalidad para conducirse en el medio interno o externo, aquellos que pertenecen a grupos sometidos o disminuidos tendrán una autoestima social mellada.

La intervención en el Perú del gobierno español por casi tres siglos produjo un cambio radical; la conducción del país ya no fue planeada en beneficio de sus habitantes nativos. Se trasladaron políticas de gobierno de otras realidades que fueron afectando al sistema social nativo, de trayectoria milenaria. Los cambios políticos, sociales, económicos $\mathrm{y}$, en lo cultural, la denominada persecución de idolatrías, con su veto a ceremonias religiosas, relatos míticos, cánticos y bailes populares, etc., atentaron contra la afirmación cultural de los pueblos y fueron disminuyendo la autoestima de sus habitantes. Los resultados negativos no se hicieron esperar: la productividad alcanzada en períodos prehispánicos disminuyó notablemente y los logros científicos y tecnológicos fueron perdiéndose conforme se desestructuraba el sistema político que los sostenía. Pero la atención puesta por el gobierno virreinal en la extracción de los recursos minerales, en relación con los intereses económicos de la metrópoli, no cambió con la independencia del Perú y la instalación de los gobiernos republicanos.

Perdida la estructura organizativa -mantenida con gran acierto por el imperio Inca- $y$ mellada la autoestima de los peruanos, los gobernantes de turno instalaron débiles sistemas organizativos y priorizaron la relación con sistemas políticos foráneos. Me atrevo a decir que desde el fin del imperio Inca, los funcionarios del gobierno no han vuelto a mirar al país desde la identidad del peruano y a reconocer su realidad geográfica y cultural tan diversa, pero también sumamente frágil. Por ello, no se ha identificado la necesidad de reestructurar el sistema organizativo, que articulaba a los habitantes en trabajos de beneficio común.

Enfrentados en forma aislada a la supervivencia y en condiciones de fuerte desigualdad, la población peruana no cree que las grandes obras monumentales, admiradas por turistas de todo el mundo, hayan sido hechas por nuestros antepasados. Las atribuyen al trabajo de los gentiles, seres sobrenaturales, de tamaño gigante. Con preocupante recurrencia se puede verificar que no se asume la posibilidad que seres humanos 
erigieran tales construcciones porque nosotros no tenemos similar capacidad.

Así como una persona adulta puede quedar limitada en su desenvolvimiento por desajustes emocionales ocurridos en su proceso de socialización, igualmente los miembros de una nación resultan afectados en su autoestima social por situaciones históricas, al punto de sentirse incapaces de resolver sus propios problemas.

En este aspecto, el patrimonio arqueológico puede ser utilizado como tratamiento terapéutico que le permita reconocer a una población sus valores culturales tradicionales, identificarse a través de ellos como integrantes de la misma nación y mejorar su autoestima social.

\section{EL PATRIMONIO ARQUeOLógico COMO FUENTE DE INGRESO ECO- NÓMICO}

Como se ha señalado el turismo representa en la economía mundial la industria sin chimeneas más rentable, inclusive que las industrias automotriz o petrolera. En esa percepción numerosos países han ubicado a la actividad turística en lugar prioritario dentro de sus planes de gobierno. En 1995 Francia fue visitada por 60 millones de turistas, y España por 45 millones. En América, en 1997 México sumó 23 millones de turistas y obtuvo 7 mil millones de dólares por este concepto. Chile fue visitado por un millón 693 turistas y recibió 1080 millones de dólares. El Perú, en cambio, no ha llegado todavía al millón de turistas.

Según informe de CENFOTUR Y PROMPERÚ, basado en una muestra de 1750 turistas entrevistados, el $85 \%$ eligió al país como destino turístico atraído por los monumentos arqueológicos; el $15 \%$ por ecoturismo. No obstante, todavía no se asu- me con suficiente convicción que los bienes arqueológicos constituyen nuestra principal fortaleza en este campo de la actividad económica. Algunos siguen proponiendo la promoción de playas o casinos de juego como centros de atracción turística, pretendiendo competir con países de Centroamérica que han desarrollado por varias décadas ese rubro, conscientes que debían hacerlo antes de que el Perú aprovechara de su potencial turístico.

Los bienes arqueológicos pueden ser una importante fuente de recursos económicos, generadora de una serie de actividades económicas y de oportunidades de empleo estable, al punto de constituirse en palanca del desarrollo rural y urbano. Sin embargo, debido a la falta de una política integral se ha venido dando atención a aspectos colaterales, como la implementación de hostales o posadas, de restaurantes, publicidad, etc., desde las entidades estatales relacionadas con turismo, muchas veces sin conexión entre ellas, y se ha dejado de lado al patrimonio arqueológico que constituye el foco del atractivo turístico.

Para que un sitio arqueológico sea apreciado por turistas nacionales o foráneos debe ser puesto en valor, tarea que pasa por atender:

1. la investigación del sitio cuyos monumentos se desean presentar para que éstos puedan transmitir su historia;

2. la conservación, de modo que los monumentos sean apreciados adecuadamente sin que se deterioren o destruyan al estar expuestos;

3. el manejo correcto del sitio arqueológico con el fin de que éste pueda ser usado por los turistas, sin que se afecte su integridad, en relación con sus otros valores, histórico y cultural. 
Se espera que el Instituto Nacional de Cultura asuma los trabajos necesarios para su adecuada presentación, pero no se le ha dotado de los medios económicos ni se le da participación en los ingresos provenientes del turismo.

Debe puntualizarse, sin embargo, que la importancia económica del patrimonio arqueológico como fuente de ingresos para mejorar las condiciones de vida de las poblaciones, no debe llevarnos a una gestión de ellos en detrimento de sus valores histórico y cultural, igualmente importantes. Debe hacerse de este recurso, que no es renovable, un uso racional que garantice su conservación para disfrute de las generaciones venideras. Con esta visión se necesitan políticas de enfoque integral para el adecuado tratamiento del turismo en el Perú.

\section{LOS RIESGOS DE LOS BIENES ARQUEOLÓGICOS}

Si bien somos herederos de un valioso patrimonio arqueológico, éste es un recurso no renovable, que viene siendo agotado por la destrucción y el saqueo.

En las últimas tres décadas el Perú ha perdido el $60 \%$ de sus bienes culturales patrimoniales, mucho más que durante los tres siglos del gobierno virreinal. Se ha dicho que todo el Perú es arqueológico, que el progreso no debe detenerse por las ruinas y que la cultura material de los muertos debe dar paso a la cultura de los vivos.

Cabe, sin embargo, señalar que, si bien no todos los asentamientos arqueológicos tienen valor turístico, todos sin excepción poseen valor histórico y, por esta calidad, deben ser estudiados para extraer la información que cada uno de ellos guarda y reconstruir la historia de las sociedades que los habitaron. Acabar con un monumento sin que se haya realizado su estudio es como quemar las páginas de un manuscrito no publicado.

Muchos son los factores que han atentado contra la conservación de los sitios arqueológicos, pero uno de los más demoledores ha sido el vertiginoso desarrollo urbano, que se ha dado sin ninguna planificación ni ordenamiento territorial ante la indiferencia de los gobiernos municipales. Han intervenido las urbanizadoras, los traficantes de tierras y los invasores marginales.

No se puede omitir la destrucción por parte de los huaqueros, quienes llevados por la extrema pobreza buscan paliar su miseria con la profanación y saqueo de monumentos, la mayor de las veces propiciados por los traficantes nacionales e internacionales, quienes son los que lucran con esta ilícita actividad.

Han causado también destrucción las empresas mineras, agrícolas, y la misma afluencia masiva de turistas a sitios arqueológicos donde no se han implementado circuitos adecuados o no se han tomado medidas de protección de los monumentos y su entorno natural y social.

El afán de lucro, los desajustes de identidad y la ignorancia sobre los valores del patrimonio arqueológico llevaron a la destrucción de los antiguos asentamientos, templos, palacios y cementerios, acabando con una historia milenaria, antes que ella pudiera ser investigada.

\section{LOS DISPOSITIVOS LEGALES}

Desde los primeros días de la Independencia se han desplegado esfuerzos para proteger el patrimonio arqueológico. El análisis histórico revela, sin embargo, una permanente lucha entre fuerzas políticas y socia- 
les, en un caso integrada por grupos conscientes de la importancia histórica, cultural y económica de este patrimonio, y en otro caso por grupos alienados, sin identificación con esta tradición cultural, que sólo han considerado la relevancia económica y se han arrogado la propiedad sobre bienes culturales con fines de lucro. Producto de esta doble actitud se observa que, sobreponiéndose a normas legales e instituciones creadas para fomentar la investigación, conservación y defensa del patrimonio arqueológico nacional, como fue la Ley 6634 de 1929, se puede constatar la existencia de normas que han dejado en el más absoluto desamparo al patrimonio arqueológico nacional, como lo hace la actual Ley 24047, de 1985 . Asimismo, se constata la gestión indiferente de algunos gobiernos que han permitido la destrucción y saqueo.

En 1998 se emitieron tres dispositivos legales que han puesto en peligro la conservación de los Monumentos Arqueológicos:

1. El Decreto Supremo No 017-98-PCM, promulgado el 07 de mayo, sobre la formalización de los asentamientos que se encuentran ocupando zonas arqueológicas, encargada a COFOPRI (Comisión de Formalización de la Propiedad Informal).

2. La Ley $\mathrm{N}^{\circ} 26961$, del 29 de mayo de ese año, para el desarrollo de la actividad turística, que supedita los valores históricos y culturales frente al valor turístico. No otorga ningún incentivo que fomente la inversión en la puesta en valor integral y le deja al INC la responsabilidad de garantizar la adecuada presentación del atractivo turístico.

3. El Decreto Supremo $N^{\circ} 008$, del 05 de junio, que otorga tierras eriazas aun cuando éstas contengan monumentos arqueológicos si el Instituto Nacional de Cultura no presentase el dispositivo legal o administrativo que declare la intangibilidad del área res- pectiva, y que haya sido emitido con anterioridad a la fecha de su oposición.

\section{LA PARTICIPACIÓN DEL ESTADO EN LA CONSERVACIÓN DEL PATRI- MONIO ARQUEOLÓGICO}

A la fecha, ninguna de las instituciones estatales tiene un programa sustentado que combine la investigación, la conservación y el desarrollo del turismo cultural. No se está aplicando un plan de manejo de los monumentos arqueológicos en el ámbito nacional. Cabe mencionar, por ejemplo, el caso de Machu Picchu: un millón quinientos mil dólares hubo de ingreso en 1998 por las visitas de turistas a ese lugar. La distribución de este beneficio fue: $10 \%$ a la Municipalidad de Aguas Calientes; 13\% en la administración del santuario y $77 \%$ para el INC. La mayor parte de esta suma ha servido para cubrir las deficiencias presupuestales de esta institución, en lugar de ser invertida en la puesta en valor de otros bienes patrimoniales.

Por otro lado, el Estado peruano no ha cumplido con implementar una eficaz administración del recurso arqueológico del Perú. Se carece de un proyecto general para la adecuada gestión de los monumentos arqueológicos. No se tiene siquiera un registro o inventario de los bienes arqueológicos a escala nacional y los pocos catastros o inventarios efectuados no han sido confrontados con la realidad y no se han aplicado sanciones por la desaparición de muchos de los sitios arqueológicos.

Debido a la campaña mundial por la protección de los recursos naturales y porque se hagan los necesarios estudios sobre impacto ambiental antes de la ejecución de una obra, algunos sectores públicos han incluido al recurso arqueológico en esa exigencia. Como respuesta, el Instituto Nacional 
de Cultura viene convocando a los profesionales del medio para la realización de los trabajos de evaluación y de liberación arqueológica. No se cuenta, sin embargo, con la normatividad clara para una adecuada ejecución y esto ha derivado en una destrucción oficial del patrimonio arqueológico, pues los materiales excavados por medio de estas acciones se depositan, en el mejor de los casos, en los almacenes de los museos estatales, pero no se cautela que ellos sean procesados y convertidos en información histórica.

El proyecto de cada liberación debe tener presupuestado el trabajo necesario con los materiales extraídos, una vez concluida la excavación. No hacerlo, como hasta ahora ocurre, no diferencia en nada la destrucción que vienen ocasionando los arqueólogos a los monumentos arqueológicos, de aquella causada por los huaqueros o saqueadores de objetos culturales.

Como hemos señalado, los bienes arqueológicos tienen valores histórico, cultural y económico y su manejo o gestión debe darse en justo equilibrio para garantizar su preservación.
Consideramos que se debe aprovechar el importante patrimonio arqueológico como recurso turístico para impulsar el desarrollo económico del Perú, pero el manejo y uso de este recurso debe ser racional y sostenible para asegurar su conservación como patrimonio cultural nacional, a cuyo beneficio tienen derecho todos los peruanos de hoy y de mañana.

Debe ser tarea del Estado invertir directamente o propiciar la participación de la empresa privada mediante incentivos tributarios en la puesta en valor de los monumentos arqueológicos. Considerar tales costos como gastos y no como inversiones es desconocer los valores de estos bienes patrimoniales. Y ningún país podrá salir de sus problemas de desarrollo si no enfrenta simultáneamente los vinculados con la autoestima de sus habitantes.

A través del patrimonio arqueológico afirmamos nuestra autoestima social, nos identificamos como integrantes de un proceso cultural y nos sentimos comprometidos con su destino. Sin él quedaremos vacíos e inseguros, sin valores y sin proyectos de vida compartidos. 